\title{
Extensive characterization of Campylobacter jejuni chicken isolates to uncover genes involved in the ability to compete for gut colonization
}

\author{
Alexandre Thibodeau ${ }^{1,2,3^{*}}$, Philippe Fravalo ${ }^{1,2,3}$, Eduardo N. Taboada ${ }^{5}$, Sylvette Laurent-Lewandowski ${ }^{1,2}$,
} Evelyne Guévremont ${ }^{3,4}$, Sylvain Quessy ${ }^{1,2,3}$ and Ann Letellier ${ }^{1,2,3^{*}}$

\begin{abstract}
Background: Campylobacter jejuni is responsible for human foodborne enteritis. This bacterium is a remarkable colonizer of the chicken gut, with some strains outcompeting others for colonization. To better understand this phenomenon, the objective of this study was to extensively characterize the phenotypic performance of $C$. jejuni chicken strains and associate their gut colonizing ability with specific genes.

Results: $C$. jejuni isolates $(n=45)$ previously analyzed for the presence of chicken colonization associated genes were further characterized for phenotypic properties influencing colonization: autoagglutination and chemotaxis as well as adhesion to and invasion of primary chicken caecal cells. This allowed strains to be ranked according to their in vitro performance. After their in vitro capacity to outcompete was demonstrated in vivo, strains were then typed by comparative genomic fingerprinting (CGF). In vitro phenotypical properties displayed a linear variability among the tested strains. Strains possessing higher scores for phenotypical properties were able to outcompete others during chicken colonization trials. When the gene content of strains was compared, some were associated with different phenotypical scores and thus with different outcompeting capacities. Use of CGF profiles showed an extensive genetic variability among the studied strains and suggested that the outcompeting capacity is not predictable by CGF profile.

Conclusion: This study revealed a wide array of phenotypes present in C. jejuni strains, even though they were all recovered from chicken caecum. Each strain was classified according to its in vitro competitive potential and its capacity to compete for chicken gut colonization was associated with specific genes. This study also exposed the disparity existing between genetic typing and phenotypical behavior of $C$. jejuni strains.
\end{abstract}

Keywords: Campylobacter jejuni, Chicken, Colonization, CGF typing, Autoagglutination, Chemotaxis, Adhesion and invasion, Competition

\section{Background}

Campylobacter jejuni is the bacterial agent responsible for campylobacteriosis, a severe gastro-enteritis afflicting humans. Campylobacteriosis may be acquired via the consumption of contaminated food [1]. Poultry meat products are one of the most important vectors of $C$. jejuni to humans [2,3]. High numbers of $C$. jejuni can colonize the chicken caecum, up to $10^{9} \mathrm{CFU} / \mathrm{g}$ of caecal

\footnotetext{
* Correspondence: alexandre.thibodeau@live.ca; ann.letellier@umontreal.ca 'Department of Pathology and Microbiology, NSERC Industrial Research Chair in Meat-Safety (CRSV), University of Montreal, Veterinary Medicine Faculty, Saint-Hyacinthe, QC, Canada

Full list of author information is available at the end of the article
}

matter [4]. Despite being present in such quantities, the bacterium mostly causes no harm to its avian host [4]. The mechanisms employed by the bacteria to colonize the chicken intestine are still not fully understood. Moreover, it was demonstrated that different $C$. jejuni strains do not have the same ability to colonize a chicken, with some strains outcompeting others when colonizing chicken cecum $[5,6]$.

Many studies have reported the importance of certain phenotypic properties for efficient $C$. jejuni chicken colonization [7]. Individually, it was reported that the autoagglutination [8], chemotaxis [7,9], adhesion [7], and 
Table 1 Campylobacter jejuni strain global comparison

\begin{tabular}{|c|c|c|c|c|c|c|c|c|}
\hline \multirow{2}{*}{$\begin{array}{l}\text { Strain } \\
\text { (Strain } \\
\text { number) }\end{array}$} & \multicolumn{5}{|c|}{ Phenotypical properties } & \multicolumn{3}{|c|}{ k-means partitioning } \\
\hline & $\begin{array}{l}\text { Adh } \\
\text { rank }\end{array}$ & $\begin{array}{l}\text { Inv } \\
\text { rank }\end{array}$ & $\begin{array}{l}\mathrm{Chm} \\
\text { rank }\end{array}$ & $\begin{array}{l}\text { Agg } \\
\text { rank }\end{array}$ & $\begin{array}{l}\text { Mean } \\
\text { rank }\end{array}$ & $\begin{array}{l}\text { Group } \\
1\end{array}$ & $\begin{array}{l}\text { Group } \\
2\end{array}$ & $\begin{array}{l}\text { Group } \\
3\end{array}$ \\
\hline D2008b (1) & 1 & 1 & 14 & 10 & 7 & + & & \\
\hline P2003a (2) & 4 & 31 & 1 & 3 & 10 & + & & \\
\hline$F 2008 c(3)$ & 10 & 12 & 9 & 13 & 11 & + & & \\
\hline F2008a (4) & 3 & 16 & 2 & 25 & 12 & + & & \\
\hline$\underline{B 2008 \mathrm{C}^{1}} \underline{(5)}$ & 9 & 3 & 23 & 12 & 12 & + & & \\
\hline M2003b (6) & 23 & 7 & 19 & 6 & 14 & + & & \\
\hline P2003b (7) & 39 & 13 & 3 & 1 & 14 & + & & \\
\hline O2003b (8) & 6 & 27 & 11 & 15 & 15 & + & & \\
\hline X2003 (9) & 15 & 4 & 7 & 34 & 15 & & + & \\
\hline E2008b (10) & 8 & 8 & 16 & 29 & 15 & & + & \\
\hline K2003a (11) & 20 & 23 & 8 & 11 & 16 & + & & \\
\hline T2003c (12) & 5 & 44 & 4 & 9 & 16 & + & & \\
\hline S2003a (13) & 14 & 20 & 24 & 5 & 16 & + & & \\
\hline U2003b (14) & 13 & 6 & 44 & 7 & 18 & & + & \\
\hline$\underline{B 2008 b^{2}} \underline{(15)}$ & 12 & 22 & 25 & 14 & 18 & + & & \\
\hline $81-176(16)$ & 16 & 11 & 28 & 19 & 19 & & + & \\
\hline B2008a (17) & 19 & 5 & 21 & 30 & 19 & & + & \\
\hline E2008c (18) & 18 & 9 & 5 & 43 & 19 & & + & \\
\hline T2003b (19) & 17 & 14 & 10 & 37 & 20 & & + & \\
\hline C2008a (20) & 7 & 18 & 31 & 31 & 22 & & + & \\
\hline$\underline{\mathrm{D} 2008 \mathrm{a}^{3}} \underline{(21)}$ & 2 & 26 & 36 & 24 & 22 & & + & \\
\hline W2003a (22) & 24 & 2 & 43 & 20 & 22 & & + & \\
\hline H2008a (23) & 22 & 17 & 27 & 23 & 22 & & + & \\
\hline I2008c (24) & 33 & 29 & 34 & 2 & 25 & & & + \\
\hline R2003 (25) & 31 & 38 & 15 & 17 & 25 & & & + \\
\hline C2008b (26) & 26 & 10 & 30 & 36 & 26 & & + & \\
\hline F2008b (27) & 30 & 28 & 6 & 39 & 26 & & & + \\
\hline A2008C (28) & 37 & 35 & 17 & 22 & 28 & & & + \\
\hline J2003a (29) & 44 & 30 & 32 & 8 & 29 & & & + \\
\hline K2003b (30) & 21 & 34 & 38 & 21 & 29 & & & + \\
\hline N2003b (31) & 38 & 32 & 12 & 32 & 29 & & & + \\
\hline I2008b (32) & 27 & 43 & 40 & 4 & 29 & & & + \\
\hline L2003b (33) & 29 & 19 & 22 & 45 & 29 & & + & \\
\hline N2003a (34) & 43 & 25 & 20 & 28 & 29 & & & + \\
\hline Q2003a (35) & 42 & 40 & 18 & 16 & 29 & & & + \\
\hline A2008d (36) & 45 & 15 & 29 & 27 & 29 & & & + \\
\hline$J 2003 b(37)$ & 11 & 41 & 33 & 33 & 30 & & & + \\
\hline H2008c (38) & 41 & 24 & 13 & 42 & 30 & & & + \\
\hline T2003a (39) & 25 & 21 & 45 & 35 & 32 & & + & \\
\hline O2003a (40) & 35 & 42 & 39 & 18 & 34 & & & + \\
\hline$\underline{F 2008 d^{3}} \underline{(41)}$ & 28 & 33 & 37 & 41 & 35 & & & + \\
\hline L2003a (42) & 34 & 39 & 26 & 44 & 36 & & & + \\
\hline
\end{tabular}


Table 1 Campylobacter jejuni strain global comparison (Continued)

\begin{tabular}{lllllll}
\hline $\mathrm{G}_{2008 \mathrm{~b}^{1}}(43)$ & 32 & 45 & 42 & 26 & 36 & + \\
$\mathrm{G} 2008 \mathrm{C}(44)$ & 36 & 36 & 35 & 40 & 37 \\
$\mathrm{~A} 2008 \mathrm{a}^{2}(45)$ & 40 & 37 & 41 & 38 & 39 & + \\
\hline
\end{tabular}

Strain identification begins with a letter (example $\mathbf{H 2 0 0 8 b )}$ representing the lot origin, followed by the year (example $\mathrm{H} \mathbf{2 0 0 8}$ ) of sampling, and ends with an identification letter (example $\mathrm{H} 2008$ b) to differentiate between strains isolated from the same lot; The strain number represents the strain ability to compete for chicken colonization with strain number 45 being the strain presenting the best out competing potential; $\mathrm{Agg}=$ autoagglutination; $\mathrm{Chm}=$ chemotaxis; Inv = invasion; Adh = adhesion; Strains underlined and sharing the same superscript were the strains co-inoculated in the chicken colonization competition assay.

invasion [10] properties of a given strain influence its capacity to colonize the chicken gut. Unfortunately, no information is available on the distribution, interaction, and relative importance of these properties in field strains. While several genes have been identified as involved in chicken colonization, many of these are unequally distributed or show sequence diversity among chicken strains [11]. Their contribution to the outcompeting capacity of a given strain has yet to be described [12].

The aim of this study was to extensively characterize multiple chicken isolated $C$. jejuni strains for phenotypical properties in order to examine the possible association between these characteristics and the ability of chicken C. jejuni strains to outcompete others during colonization. Based on a previous characterization of these strains regarding chicken associated colonization genes, we also evaluated the association between a strain outcompeting capacity and its gene content.

\section{Method}

\section{Strains and media}

Sampling and identification of the isolates were done as previously described [11] from chicken caecal content recovered at slaughterhouses. A total of 45 C. jejuni isolates were used in this study. Confirmed $C$. jejuni isolates were frozen in multiple aliquots at $-80^{\circ} \mathrm{C}$ in Brucella broth (Innovation Diagnostic Inc., Montreal, Canada) containing $0.1 \%$ Agar (Innovation Diagnostic Inc.) and $25 \%(v / v)$ glycerol. Strain C. jejuni 81-176, used as a positive control, was kindly supplied by Dr. Shaun Cawthraw, Veterinary Laboratories Agency, UK. Strains were cultured on mCCDA (Innovation Diagnostic Inc.), Mueller Hinton Agar (Oxö̈d, Nepean, Ontario, Canada), or Trypticase Soy agar (TSA) supplemented with $5 \%(v / v)$ sheep blood (Fisher Scientific, Ottawa, Ontario, Canada) and incubated in a microaerobic atmosphere using Oxoïd gas-generating system. For every characterization assay, a new $-80^{\circ} \mathrm{C}$ aliquot of the strain was used to minimize strain variation due to repeated in vitro passages.

\section{In vitro characterization}

C. jejuni strains were characterized for their ability to autoagglutinate, be attracted by mucins, and adhere to and invade chicken primary caecal cells. Each result was the mean of at least two distinct experiments, each performed in technical duplicates. For each in vitro phenotypic characterization, strains were then classified according to their phenotypical properties; the strain possessing the lowest property value (poorest performing strain) was assigned a rank value of 1 and the best one a rank value of 45 . The mean rank of the in vitro phenotypic properties (autoagglutination, chemotaxis, adhesion, and invasion) was then calculated for each strain in order to estimate the strain's chicken competition potential for the colonization of the chicken gut. Strains were numbered according to their mean rank value classification and this number was used in the figures to identify each strain position according to their phenotypical characterization. Thus strain number 45 , possessing the highest mean rank value, was expected to reveal a higher competition potential compared to all strains tested in this study (Table 1).

\section{Autoagglutination}

Autoagglutination and chemotaxis experiments were carried out as previously described [13]. For autoagglutination, overnight cultures were resuspended in PBS to an optic density (OD) $(630 \mathrm{~nm})$ of 1.0. One $\mathrm{ml}$ suspensions were incubated at room temperature for $3 \mathrm{~h}$ before the OD was remeasured. Autoagglutination was expressed as (Initial OD 630 nm - 3 h OD 630 nm)/Initial OD 630 nm X 100.

Table 2 PCR conditions for the detection of the genes specific to the strains used in the in vivo chicken colonization competition assay

\begin{tabular}{|c|c|c|}
\hline Gene & Primers $\left(5^{\prime}-3^{\prime}\right)$ & Cycle \\
\hline \multirow[t]{3}{*}{ pseD } & F: GATGGAATGGTAAGCGTTGCACA & $95^{\circ} \mathrm{C}$ for $20 \mathrm{~s}$ \\
\hline & R: TTATCCTTGCTCCACCTTCGGTGC & $56^{\circ} \mathrm{C}$ for $20 \mathrm{~s}$ \\
\hline & & $72^{\circ} \mathrm{C}$ for $20 \mathrm{~s}$ \\
\hline \multirow[t]{3}{*}{ virB11 } & F: TCTTGTGAGTTGCCTTACCCCTTIT & $95^{\circ} \mathrm{C}$ for $20 \mathrm{~s}$ \\
\hline & R: CCTGCGTGTCCTGTGTTATTTACCC & $65^{\circ} \mathrm{C}$ for $20 \mathrm{~s}$ \\
\hline & & $72^{\circ} \mathrm{C}$ for $20 \mathrm{~s}$ \\
\hline \multirow[t]{3}{*}{ CJ0144 } & F: TTCATGAAGTTGTGAATGCTGAAA & $95^{\circ} \mathrm{C}$ for $20 \mathrm{~s}$ \\
\hline & R: TCGCTTACAACAAGTTCGCC & $61^{\circ} \mathrm{C}$ for $20 \mathrm{~s}$ \\
\hline & & $72^{\circ} \mathrm{C}$ for $10 \mathrm{~s}$ \\
\hline
\end{tabular}

All PCR cycles were preceded by an initial denaturation step consisting of a 15 -min incubation at $95^{\circ} \mathrm{C} ;$ All PCR runs were ended by a final 5-min elongation step at $72^{\circ} \mathrm{C}$ followed by a denaturation curve analysis. 


\section{Chemotaxis}

For chemotaxis, overnight cultures were suspended to an OD of 1.0. Suspensions were mixed with an equal volume of soft agar $(0.4 \%)$. The resulting mix was then poured in a Transwell insert (BD, Mississauga, Ontario). The inserts were subsequently put in a 24-well plaque containing PBS (negative control) or porcine mucins (2 mg/ml) (Sigma-Aldrich, Oakville, Ontario, Canada) for $3 \mathrm{~h}$. The number of bacteria found in the PBS or mucins conditions was then enumerated on Mueller-Hinton Agar. Chemotaxis results were described as follows: -1 / log (number of recovered bacteria after the experiment/ number of initial bacteria used).

\section{Adhesion and invasion of primary chicken caecal cells}

Primary cells were obtained as follows, adapted from Byrne et al., 2007 [14]. Caeca collected at nearby slaughterhouses were emptied of their content, and, within an hour, transported to the laboratory in DMEM (Invitrogen) containing $1 \%$ FBS $(v / v)$ (Hyclone, Fisher Scientific), 200 units/ml of penicillin/streptomycin (Sigma-Aldrich), and $50 \mu \mathrm{g} / \mathrm{ml}$ of gentamicin (Sigma-Aldrich). After five washes in HBSS, caeca were cut into small pieces and digested using $375 \mathrm{U} / \mathrm{ml}$ of collagenase (Sigma-Aldrich) and $1 \mathrm{U} / \mathrm{ml}$ of dispase (Sigma-Aldrich) for $3 \mathrm{~h}$ at $37^{\circ} \mathrm{C}$ in DMEM supplemented with $1 \%$ FBS $(v / v), 200$ units $/ \mathrm{ml}$ of penicillin/ streptomycin, and $50 \mu \mathrm{g} / \mathrm{ml}$ of gentamicin. Floating crypts were pelleted by centrifugation at $50 \times g$ for $4 \mathrm{~min}$. The cells were purified by suspending the pellet in HBSS containing $2 \%$ D-Sorbitol $(v / v)$ (Fischer Scientific) and then centrifuged at $50 \mathrm{x} \mathrm{g}$ for $4 \mathrm{~min}$. After four purification steps, cells were seeded (3000 crypts per well) in 24-well cell culture plates (Fisher Scientific) using a culture media composed of DMEM supplemented with $10 \%$ FBS $(v / v)$, $1.4 \mu \mathrm{g} / \mathrm{ml}$ of hydrocortisone (Sigma-Aldrich), $10 \mu \mathrm{g} / \mathrm{ml}$ of insulin (Sigma-Aldrich), $5 \mu \mathrm{g} / \mathrm{ml}$ of transferrin (Sigma-Aldrich), $1 \mu \mathrm{g} / \mathrm{ml}$ of fibronectin (Sigma-Aldrich), $200 \mathrm{units} / \mathrm{ml}$ of penicillin/streptomycin, and $50 \mu \mathrm{g} / \mathrm{ml}$ of gentamicin. The culture was incubated at $38^{\circ} \mathrm{C}$ in a $6 \%$ $\mathrm{CO}_{2}$ atmosphere. Half of the cell culture media was

Table 3 Identification of the dominant Campylobacter jejuni strains in the in vivo chicken colonization competition assays by PCR detection of relevant genes

\begin{tabular}{|c|c|c|c|c|c|c|c|c|}
\hline Group and assay & Sample & Sample type & $\operatorname{arsC}$ & virB11 & cj0144 & tetO & rloB & cje0256 \\
\hline Group1- assay1 & Bird1 & bird feces & + & - & + & + & + & - \\
\hline Group1- assay1 & Bird2 & bird feces & + & - & + & + & + & - \\
\hline Group1- assay1 & Bird3 & bird feces & + & - & + & + & + & - \\
\hline Group1- assay2 & Bird1 & bird feces & + & - & + & + & + & - \\
\hline Group1- assay2 & Bird2 & bird feces & + & - & + & + & + & - \\
\hline Group1- assay2 & Bird3 & bird feces & + & - & + & + & + & - \\
\hline Group1- assay 1 + 2 & G2008b & inoculated strain DNA & + & - & + & + & + & - \\
\hline Group1- assay 1 + 2 & B2008c & inoculated strain DNA & - & + & - & - & - & - \\
\hline Group2- assay1 & Bird1 & bird feces & + & - & + & - & + & - \\
\hline Group2- assay1 & Bird2 & bird feces & + & - & + & - & + & - \\
\hline Group2- assay1 & Bird3 & bird feces & + & - & + & - & + & - \\
\hline Group2- assay2 & Bird1 & bird feces & + & - & + & - & + & - \\
\hline Group2- assay2 & Bird2 & bird feces & + & - & + & - & + & - \\
\hline Group2- assay2 & Bird3 & bird feces & + & - & + & - & + & - \\
\hline Group2- assay $1+2$ & A2008a & inoculated strain DNA & + & - & + & - & + & - \\
\hline Group2- assay $1+2$ & B2008b & inoculated strain DNA & - & + & - & - & - & - \\
\hline Group3- assay1 & Bird1 & bird feces & - & - & + & + & - & - \\
\hline Group3- assay1 & Bird2 & bird feces & - & - & + & + & - & - \\
\hline Group3- assay 1 & Bird3 & bird feces & - & - & + & + & - & - \\
\hline Group3- assay2 & Bird1 & bird feces & $+($ low $)$ & - & + & + & - & - \\
\hline Group3- assay2 & Bird2 & bird feces & $+($ low $)$ & - & + & + & - & - \\
\hline Group3- assay2 & Bird3 & bird feces & - & - & + & + & - & - \\
\hline Group3- assay $1+2$ & F2008d & inoculated strain DNA & - & - & + & + & - & - \\
\hline Group3- assay1 + 2 & D2008a & inoculated strain DNA & - & - & - & + & - & + \\
\hline
\end{tabular}

Detection of genes specific to the inoculated strains in the in vivo competition assays seven days post-inoculation; (+) gene detected in the sample; (-) gene not detected in the sample; (low) weak signal observed. 
replaced every two days. After seven to nine days, cells (minimum $80 \%$ confluence) were used for the characterization of $C$. jejuni isolates.

Ready to use primary caecal cells were first washed with Hank's Balanced Salt Solution (HBSS) (Invitrogen, Burlington, Ontario, Canada) and then infected with $10^{7} \mathrm{CFU}$ of C. jejuni per well. The infected cell culture was incubated for $3 \mathrm{~h}$ at $38^{\circ} \mathrm{C}$ and then washed three times with HBSS. Cells were lysed with PBS containing $0.5 \%(v / v)$ Triton X-100 (Sigma-Aldrich) and the C. jejuni recovered were enumerated on Mueller-Hinton Agar. For invasion, prior to lysis, cells were further incubated for one hour in DMEM (Invitrogen) containing $1 \%$ FBS $(v / v)$ and $50 \mu \mathrm{g} / \mathrm{ml}$ of gentamicin, a concentration lethal for all tested isolates, and then washed in HBSS three times.

\section{Competition potential}

K-means clustering was used (Gene Cluster 3.0) [15] to objectively separate the strains according their competition potential. For each strain, autoagglutination, chemotaxis, adhesion, and invasion ranks were defined as variables. The similarity metric used was the Euclidean distance, with 3 clusters and 1000 runs. A k of 3 was used as we wanted strains to split into a group of low, medium, or high competition potential, with strains showing clear opposite phenotypic properties. The resulting tree was visualized in Treeview [16].

\section{Chicken colonization and competition assays}

All animal experiments were approved by the "Comité d'éthique sur l'utilisation des animaux" (CEUA) of the Veterinary Medicine Faculty of the University of Montreal.

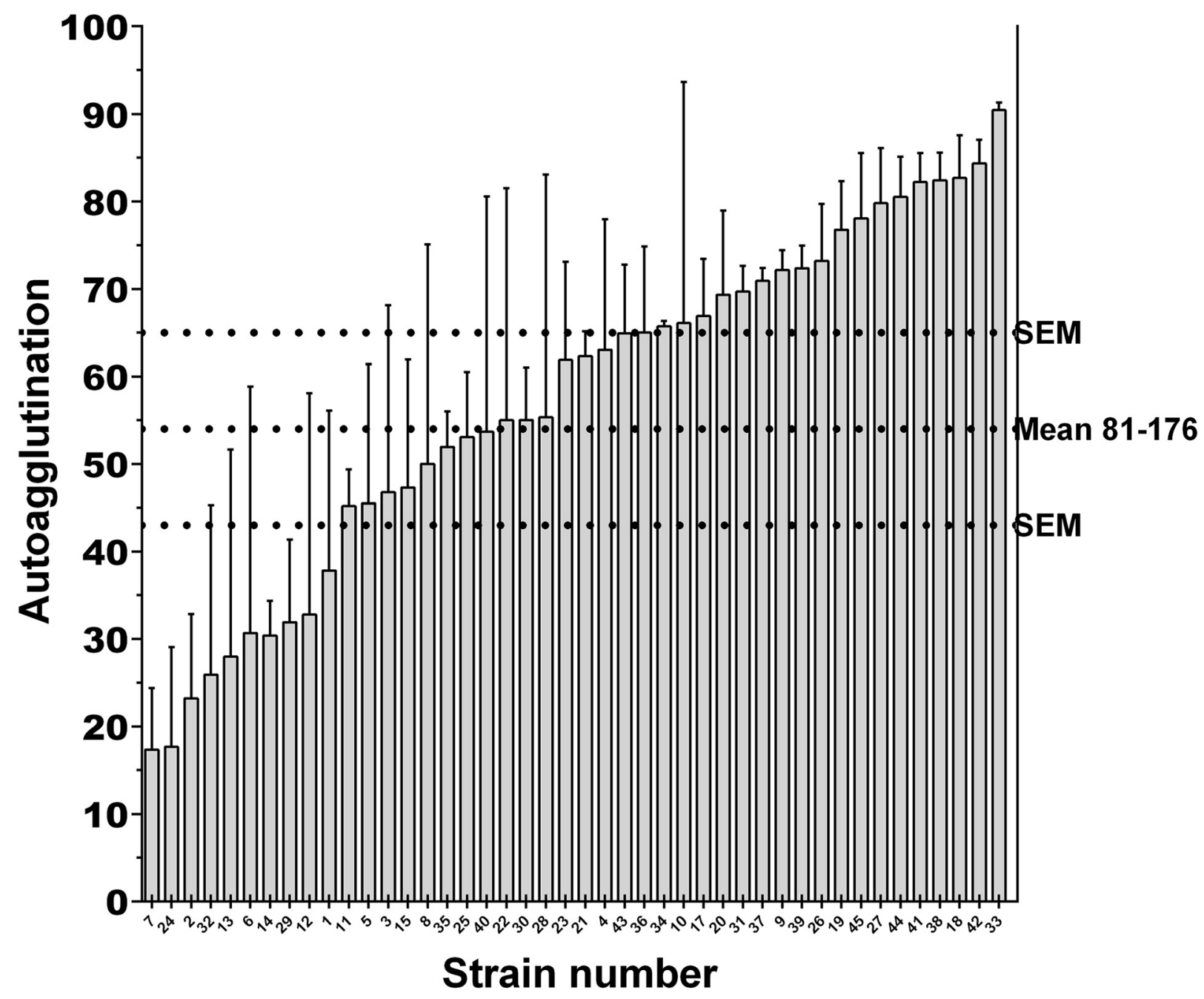

Fig. 1 Autoagglutination capacities of Campylobacter jejuni chicken strains. The error bars represent the SEM. The horizontal dashed lines represent the control strain 81-176 and its SEM. Strain results were classified by increasing order. The $x$ axis represents the strains numbered according to their final mean rank value, presented in Table 1. Strains were found with different autoagglutination properties (Kruskal-Wallis, $p=0.0083$ ). Autoagglutination is expressed as ((Initial DO $630 \mathrm{~nm}-3$ h DO $630 \mathrm{~nm}$ )/Initial DO $630 \mathrm{~nm}) \times 100$ 
Day-old chickens $(n=9)$ were separated into three groups housed in separate pens. Birds were raised on wood shavings on concrete-floored pens and had ad libitum access to water and to a standard commercial feed. Just before the inoculation, fresh caecal droppings were collected to investigate for the presence of $C$. jejuni. At 14 days of age, each chicken was simultaneously inoculated per os with a mix suspension (1:1 ratio) of two different $C$. jejuni strains possessing opposed phenotypic properties (Table 1). All inoculum were equal: approximately 4 log CFU were used for each strain per bird. The three chickens in Group A received strains $\mathrm{G} 2008 \mathrm{~b}$ and $\mathrm{B} 2008 \mathrm{c}$; the three chickens in Group B received strains A2008a and B2008b; the three chickens in Group C received strains F2008d and D2008a. All chickens were euthanized in a $\mathrm{CO}_{2}$ chamber seven days later and the concentration of caecal $C$. jejuni was enumerated on mCCDA plates. The experience was repeated once.

\section{PCR detection of challenge strains}

DNA was extracted using a standard phenol-chloroform procedure [17] from the caecal samples recovered seven days post-inoculation. The caecal samples represented the whole content of individual chicken caecal content (100 $\mu \mathrm{L}$ of $10^{-3}$ dilution) incubated $24 \mathrm{~h}$ on an mCCDA plate. The detection of genes specific to each inoculated strain was done by PCR (Table 2 and Table 3). The targeted genes were selected based on a prior microarray study [11]. DNA extracted from each inoculated strain served as controls. Standard mixes consisted of a $20 \mu \mathrm{l}$ reaction containing $1 \mathrm{X}$ QPCR master mix (MBI EVOlution EvaGreen (R), Montréal Biotech Inc.) and $350 \mathrm{~nm}$ of

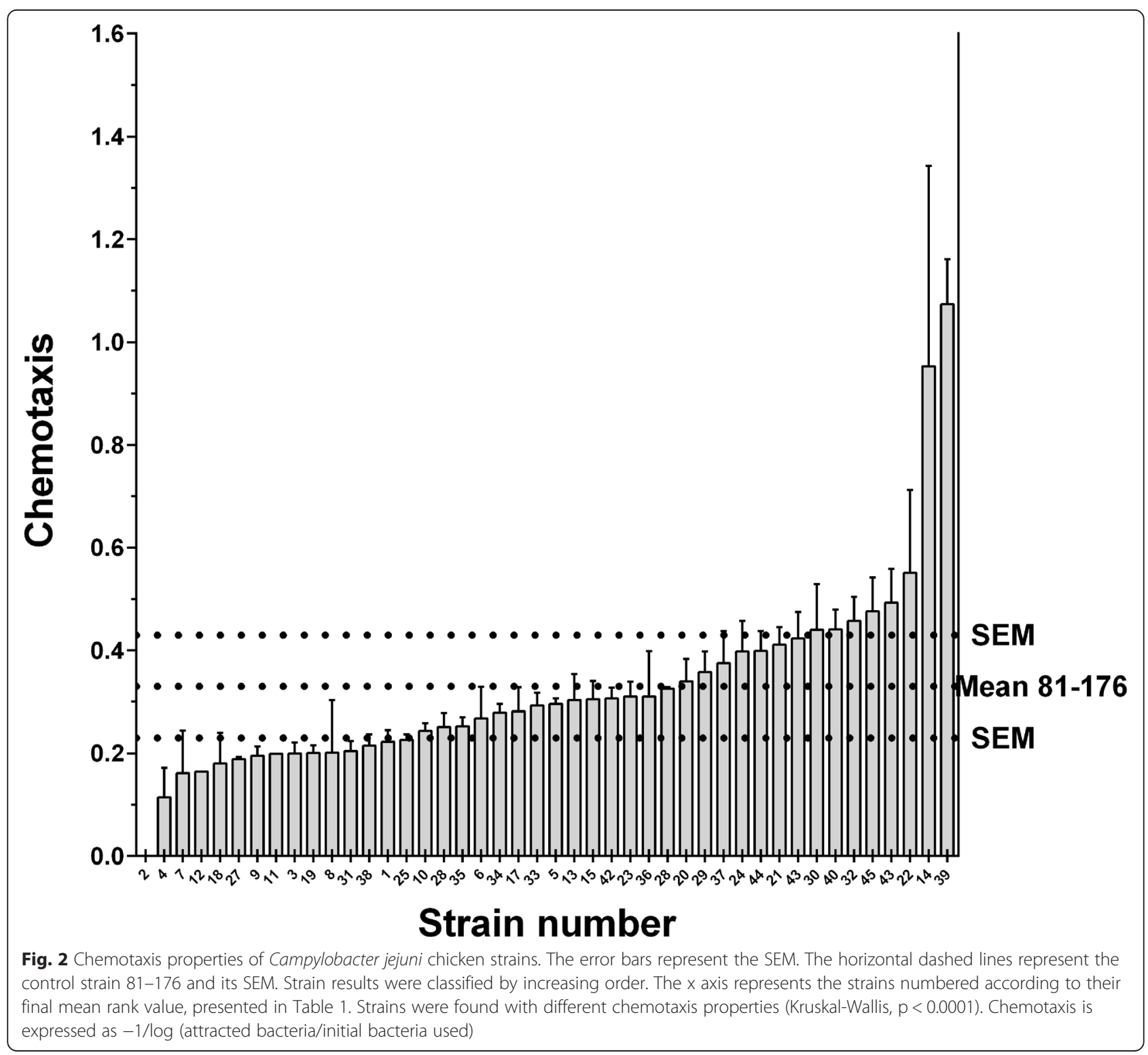


each primer. Reactions that were positive after 35 cycles were rejected.

\section{Gene association with phenotypic properties}

A total of 30 strains, originating from different chicken lots or possessing different phenotypical properties, were retained for the comparison of their evaluated gene content [11] and the mean ranking of their phenotypic properties and thus their outcompeting capacity.

First, the genes known to be present in the strain (A2008a) possessing the highest outcompeting capacity were compared with those present in the strain (D2008b) possessing the lowest outcompeting capacity (Table 1). A list of all unique genes was established for both strains. Secondly, for each identified gene from all of the 30 retained strains, the mean rank value of the strains possessing a specific gene was compared to the mean rank value of the strains lacking this same gene. This allowed for the identification of genes that were present in strains that possessed, on average, higher or lower phenotypic mean rank values and thus high or low outcompeting capacities, as illustrated in the in vivo assay.

\section{Comparative genomic fingerprinting}

To gain information about the representativity of our strain collection in Canada, all strains were subjected to CGF, a reference Campylobacter typing method, as previously described [18]. Briefly, DNA was extracted using Qiagen DNeasy Blood and Tissue kit (Qiagen, Toronto, Canada). The detection of $40 \mathrm{C}$. jejuni accessory genes was then carried out using a series of multiplex PCRs

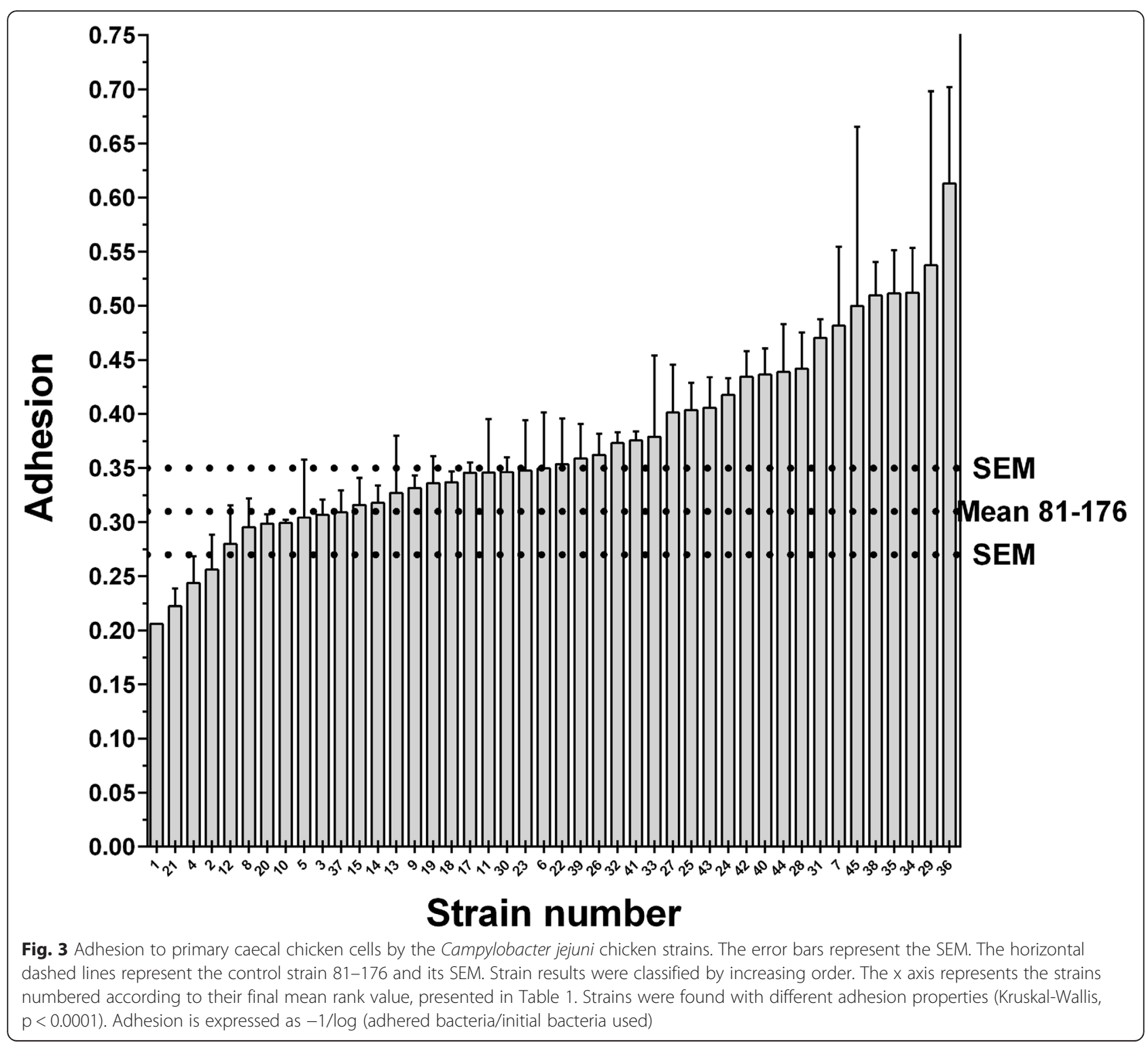


combined with QIAxcel automated electrophoresis for detection and analysis of the amplicons (Qiagen). The CGF profiles, which are based on the presence/absence of target genes, were clustered using a simple matching distance coefficient and the unweighted-pair group method using average linkages (UPGMA) of clustering in Bionumerics (v.6.1; Applied Maths, Austin, TX). CGF profiles were subsequently compared with those present in a Canadian CGF database comprising data on over 15,000 isolates from human, animal, and environmental sources (E. Taboada, personal communication).

\section{Statistical analysis}

The Kruskal-Wallis test was used to compare the strains' phenotypic properties and mean rankings. The comparison of the strains phenotypic mean ranking values, based on the presence or absence of certain genes, was done using the Mann-Whitney analysis. An alpha value lower than 0.05 was considered for genes present in strains likely to possess different mean rank values, while an alpha value lower than the alpha value divided by the number of compared genes was used to identify genes strongly associated with a strain's outcompeting capacities. All statistical analyses were computed in GraphPad Prism 6 (GraphPad, La Jolla, CA, USA).

\section{Results}

Phenotypic properties of the strains

Strains harbored different autoagglutination $(p=0.0083$, Fig. 1) as well as chemotaxis (Fig. 2) properties ( $<0.0001)$.

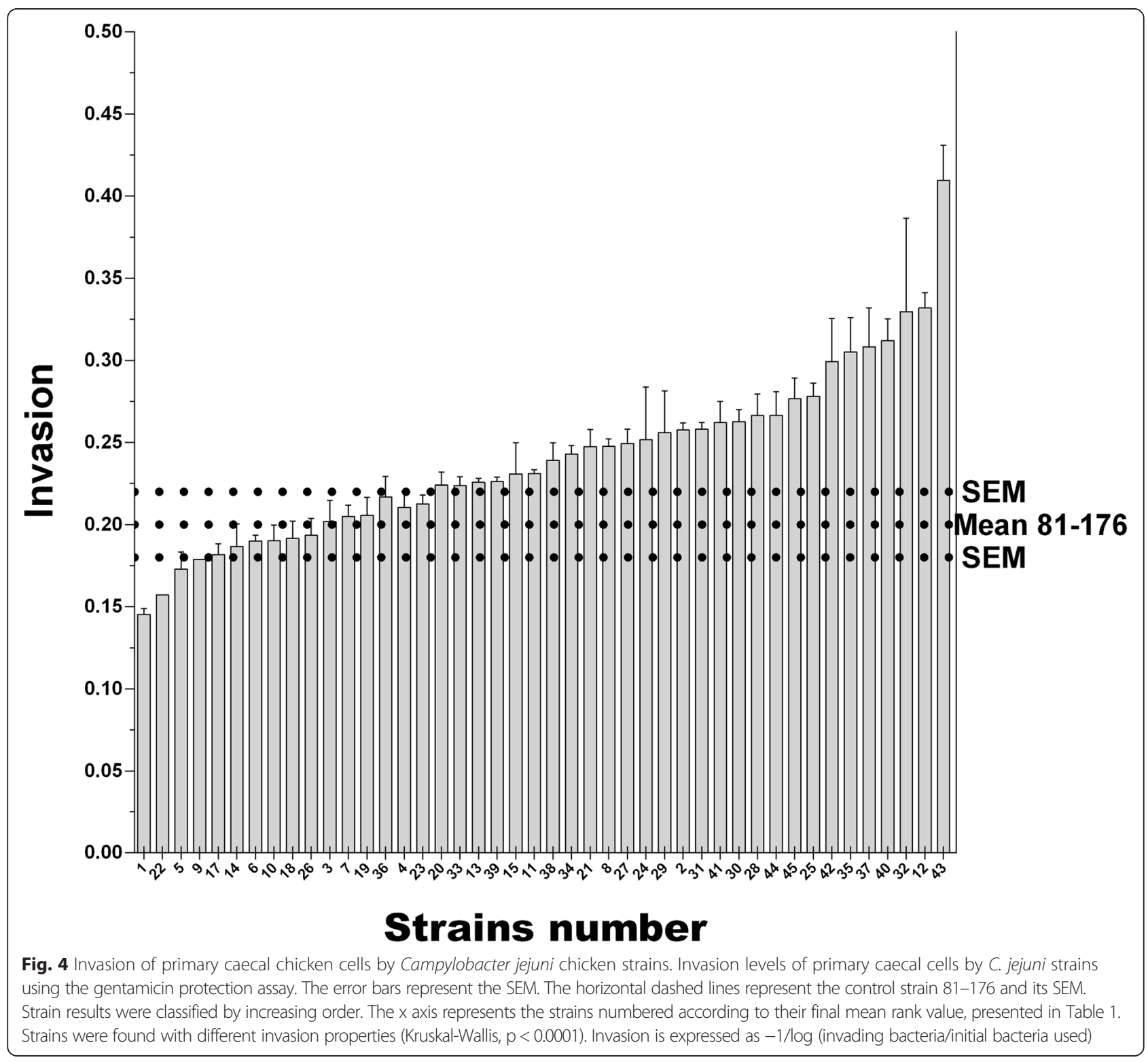


Adhesion and invasion levels (Figs. 3 and 4) to chicken caecal primary cells were also found to be variable (both $\mathrm{p}<$ 0.0001). Apart from the obvious differences in extrema, no specific group seemed to emerge from these distributions.

To take into account all chicken colonization associated phenotypic properties when comparing strains, strains were individually ranked according to their phenotypic properties and the mean rank value for all strains was calculated (Table 1). In our collection, strains displayed different mean rank values, the lowest one being 7 and the highest $39(\mathrm{p}=0.004$, Fig. 5, and Table 1).

We then used k-means partitioning to determine how strains would be objectively grouped, instead of arbitrarily choosing which strain could be considered to present a high or a low competition potential. The strain partitioning was coherent with the calculated mean rank values: group 1 was composed of strains possessing a minimum mean rank of 7 and a maximum mean rank of 18, group 2 was composed of strains possessing a minimum mean rank of 15 and a maximum mean rank of 32, while a third group was composed of strains possessing a minimum mean rank of 25 and a maximum mean rank of 39 (Table 1).

\section{Chicken colonization competition experiment}

Chickens in all groups were negative for $C$. jejuni prior to inoculation but were colonized to the same extent seven days after the co-inoculation (7 PI). For group 1,

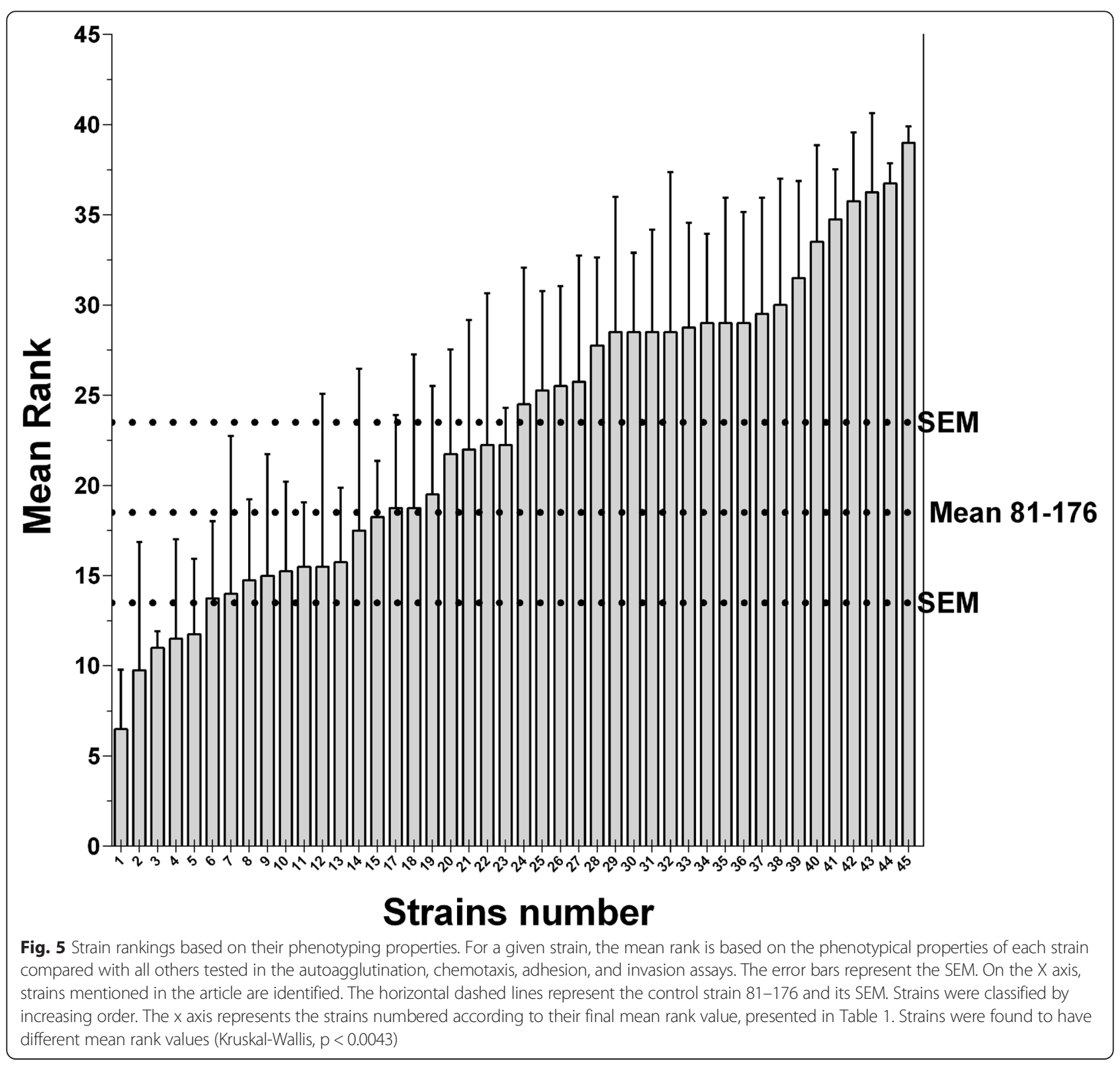


Table 4 Genes associated with Campylobacter jejuni strains possessing higher potential competition capacities

\begin{tabular}{|c|c|c|c|c|c|c|}
\hline Gene & $\begin{array}{l}\text { Rank } \\
\text { p value }\end{array}$ & $\begin{array}{l}\text { Agg } \\
p \text { value }\end{array}$ & $\begin{array}{l}\text { Chm } \\
\text { p value }\end{array}$ & $\begin{array}{l}\text { Inv } \\
\text { p value }\end{array}$ & $\begin{array}{l}\text { Adh } \\
\text { p value }\end{array}$ & Gene Function \\
\hline $\operatorname{ars} C$ & 0.001 & 0.254 & 0.007 & 0.027 & 0.037 & Arsenate reductase \\
\hline C8J1456 & 0.005 & 0.824 & 0.002 & 0.033 & 0.175 & Hypothetical protein \\
\hline C8J1083 & 0.006 & 0.788 & 0.001 & 0.063 & 0.172 & Hypothetical protein LOS locus \\
\hline$d m s A$ & 0.010 & 0.930 & 0.002 & 0.085 & 0.143 & Anaerobic dimethyl sulfoxide reductase \\
\hline rloA & 0.021 & 0.826 & 0.003 & 0.085 & 0.113 & type 1 restriction system variant \\
\hline HsdS & 0.039 & 0.857 & 0.007 & 0.221 & 0.279 & type 1 restriction system variant \\
\hline CJE1719 & 0.039 & 0.213 & 0.069 & 0.025 & 0.008 & Zinc-binding dehydrogenase family variant \\
\hline C8J0988 & 0.043 & 0.514 & 0.026 & 0.127 & 0.013 & Hypothetical protein \\
\hline
\end{tabular}

In the characterized C. jejuni strain collection, strains positive by microarray for these genes had higher mean rank values than the negative strains, as assessed by the Mann-Whitney test. An alpha value lower than 0.05 was considered for genes present in strains likely to possess different mean rank values or phenotypical properties, while an alpha value lower than 0.002 was considered for identifying genes that are of greater importance; Phenotypic properties refer to

$\mathrm{Agg}=$ autoagglutination; $\mathrm{Chm}=$ chemotaxis; Inv = invasion; $\mathrm{Adh}=$ adhesion .

group 2, and group 3, counts were $8.2 \pm 0.7,8.2 \pm 0.7$ and $8.2 \pm 0.4 \log \mathrm{CFU} / \mathrm{g}$ of caecal matter $\pm \mathrm{SEM}$, respectively. The genes unique to the strains possessing the highest competition potential were systematically detected while the others were not (Table 3).

\section{Chicken colonization gene content association with the strains' mean rank}

The gene content of the strain possessing the highest mean rank value (A2008a) was compared with the gene content of the strain possessing the lowest mean rank value (D2008b). This comparison established that 20 genes were found to be present only in the highest ranking strain (A2008a) (data not shown). Their presence was assessed in the remaining strains. Of these, eight were present among C. jejuni strains that also significantly possessed higher mean rank values than the strains lacking them (Table 4). In the corollary analysis, a total of 27 genes were found present only in the strain (D2008b) possessing the lowest mean rank value (data not shown). Of these genes, 11 were present among C. jejuni strains that significantly possessed a low mean rank value compared to the strains lacking these genes (Table 5). This allowed the identification of genes that were associated with strains presenting significantly greater or lower outcompeting capacities.

\section{CGF typing}

Out of the 45 strains analyzed in this study, 26 different CGF profiles were observed among the strains in the dataset, including three newly identified fingerprints (Additional file 1 Table S1, and Table S2). Most grouped

Table 5 Genes associated with Campylobacter jejuni strains possessing lower potential competition capacities

\begin{tabular}{|c|c|c|c|c|c|c|}
\hline Gene & $\begin{array}{l}\text { Rank } \\
\text { p value }\end{array}$ & $\begin{array}{l}\text { Agg } \\
\text { p value }\end{array}$ & $\begin{array}{l}\text { Chm } \\
\text { p value }\end{array}$ & $\begin{array}{l}\text { Inv } \\
\text { p value }\end{array}$ & $\begin{array}{l}\text { Adh } \\
\text { p value }\end{array}$ & Function \\
\hline lctP & 0.002 & 0.222 & 0.018 & 0.037 & 0.023 & L-lactate permease \\
\hline CJ1325 & 0.003 & 0.538 & 0.001 & 0.054 & 0.112 & Putative periplasmic protein \\
\hline CJE1277 & 0.004 & 0.538 & 0.002 & 0.037 & 0.087 & Putative glycosyltransferase \\
\hline CJE0171 & 0.006 & 0.796 & 0.003 & 0.070 & 0.049 & Putative TonB-dependant outer membrane receptor \\
\hline CJE1679 & 0.009 & 0.436 & 0.147 & 0.017 & 0.011 & Methyl-accepting chemotaxis protein \\
\hline CJ0223 & 0.010 & 0.983 & 0.037 & 0.002 & 0.266 & Pseudogene, putative IgA protease family protein \\
\hline motA & 0.010 & 0.920 & 0.002 & 0.085 & 0.143 & Flagellar motor proton channel possible variant \\
\hline CJE1820 & 0.012 & 0.885 & 0.011 & 0.019 & 0.039 & Putative periplasmic protein \\
\hline CJE1730 & 0.021 & 0.645 & 0.015 & 0.068 & 0.041 & Putative permease \\
\hline cfrA & 0.030 & 0.677 & 0.008 & 0.218 & 0.233 & Ferric receptor cfrA \\
\hline CJE1719 & 0.039 & 0.213 & 0.069 & 0.025 & 0.008 & Zinc-binding dehydrogenase family oxidoreductase variant \\
\hline
\end{tabular}

In the characterized C. jejuni strain collection, strains positive by microarray for these genes had lower mean rank values then the negative strains, as assessed by the Mann-Whitney test. An alpha value lower than 0.05 was considered for genes present in strains likely to possess different mean rank values or phenotypical properties, while an alpha value lower than 0.002 was considered for identifying genes that are of greater importance; Phenotypic properties refer to Agg = autoagglutination; $\mathrm{Chm}=$ chemotaxis; Inv = invasion; Adh = adhesion. 


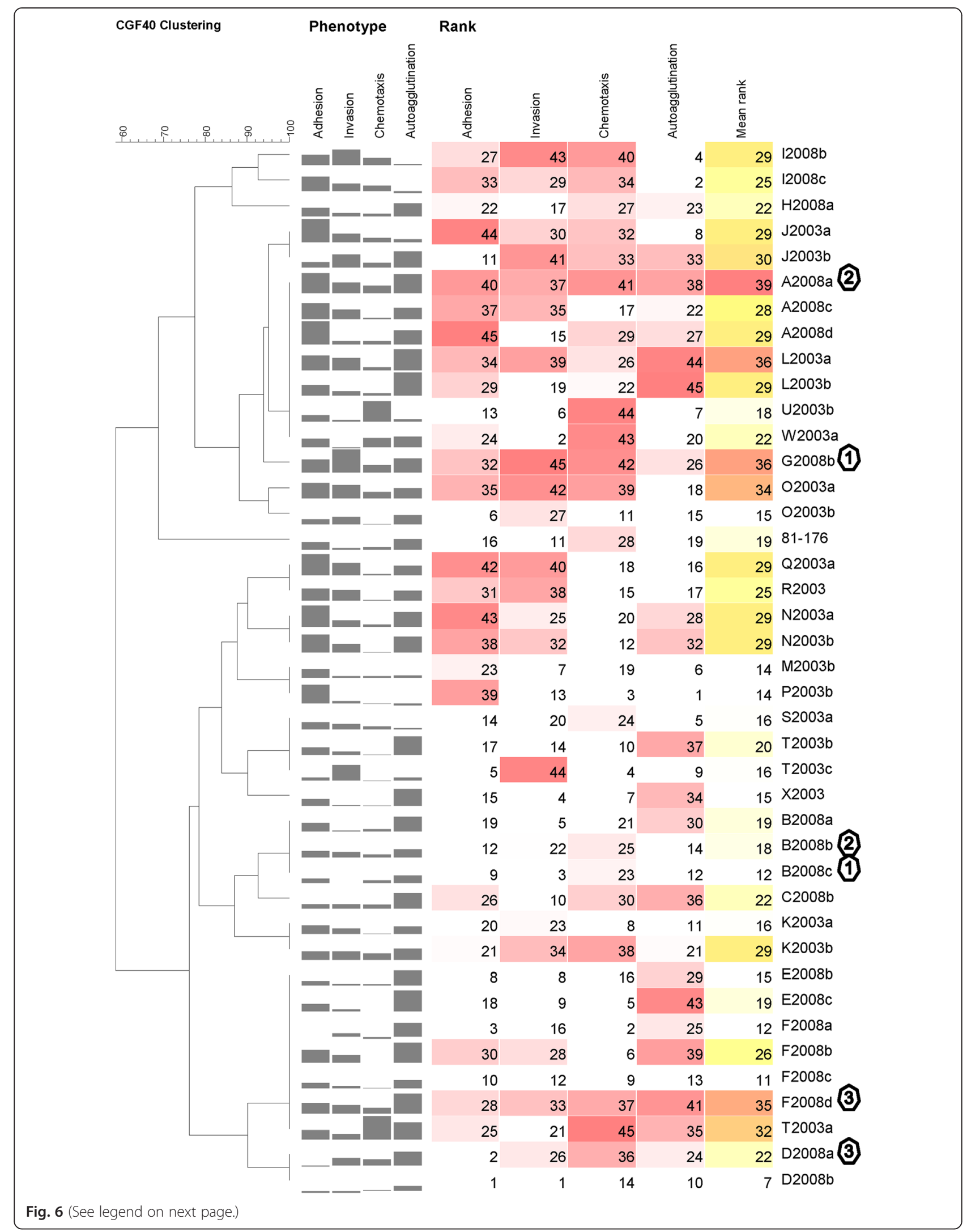


(See figure on previous page.)

Fig. 6 Strain CGF clustering, phenotype, and ranking. CGF data were used to cluster strains. For each strain, an overview of its phenotype is shown. For each property (adhesion, invasion, chemotaxis, and autoagglutination), the higher the bar is, the higher the property was. For each strain, its rank in each phenotypic assay is shown. For each assay, the strain with the lowest property was assigned a rank of 1 and the highest a rank of 45. Mean rank is the mean of all four property rank values. The darker the rank value background is, the higher the value. Strain identification begins with a letter (example $\mathbf{H}$ 2008b) representing the lot origin, followed by the year (example H2008b) of sampling and ends with an identification letter (example $\mathrm{H} 2008 \mathbf{b}$ ) to differentiate between strains isolated from the same lot. Strains sharing the same octagon number were the strains co-inoculated to each corresponding chicken group in the chicken colonization competition assay

strains also possessed similar outcompeting potential (Fig. 6).

\section{Discussion}

Various $C$. jejuni strains do not seem able to colonize the chicken gut with the same ability and the extent of this variability was unknown. This study thoroughly characterized chicken $C$. jejuni strains in an attempt to better understand the competitive advantages for chicken caecal colonization.

It has been shown that some phenotypic properties, taken individually, were important for effective chicken colonization [7]. It has also been demonstrated that strains with superior in vitro invasion capabilities can outcompete others in chicken colonization assays [10]. In our study, we characterized a collection of chicken C. jejuni strains according to 4 important phenotypic properties that may affect colonization. With this characterization, we clearly showed the variability of the autoagglutination, chemotaxis, adhesion, and invasion properties and showed that they were unexpectedly well distibuted among the tested chicken $C$. jejuni strains.

We then proposed a novel classification method that allowed us to integrate all characterized phenotypical properties when comparing sets of strains in order to better estimate their chicken competition potential. Kmeans partitioning distributed the strains in the 3 groups and was able to clearly separate strains between those that possessed the best or the poorest phenotypic properties mean rank values; strains with high mean rank values were considered as highly competitive while those with low mean rank values were expected to be poorer competitors. This demonstrated that even though all strains were initially recovered from chicken caecal content, they were quite diverse when comparing their competition potential. The strains possessing the highest competition potentials were those that also showed high autoagglutination, chemotaxis, adhesion, and invasion properties.

To corroborate that the classification of the strains according to their mean rank value reflected the chicken outcompeting capacity of the strains, an in vivo assay was carried out. Strains from the suspected high, low, and mild competition potential groups were used. This assay showed that the dominant strains were systematically the ones with the highest mean rank values and that these strains are present in the high competition potential group. Indeed strains possessing low mean rank values were not detected in the diluted $\left(10^{-3}\right)$ chicken caecal content, indicating a difference of at least $4 \mathrm{log}$ CFU/g for colonization.

These results suggested that not all of our strains were equally adapted to chicken colonization and that strains with high mean rank values would likely outcompete others during chicken colonization. The recovered strains with the lowest outcompeting capacities were probably the only ones that the sampled chickens encountered during rearing.

Comparison of the gene content of the best performing to the poorest performing strain allowed the identification of genes in strains possessing different mean rank values and thus different outcompeting capacities. Of these genes, the ars $\mathrm{C}$ gene was strongly associated with strains $(\mathrm{p}=0.001)$ possessing high mean rank values. This gene was previously identified in a study that compared the gene content of two strains possessing different colonization capacities [19]. In C. jejuni, $\operatorname{ars} \mathrm{C}$ is part of an operon conferring resistance to arsenic [20]. Arsenical compounds such as arsanilic acid were used in Canada to control coccidiosis in chicken [21]. Arsenic resistance is variable in C. jejuni strains [20]. The exact role of ars $\mathrm{C}$ in $C$. jejuni chicken colonization remains to be validated. An indirect role for $\operatorname{ars} \mathrm{C}$ in colonization has been proposed for Yersinia where arsenate resistance probably participated in the selective emergence of more specialized pig strains but was not directly involved in colonization [22].

This is, to our knowledge, the first report of genes that may be associated with different outcompeting capacities. The exact importance of these genes for competition remains to be further assessed.

The comparison of the CGF profiles obtained in the present study was made with those present in a Canadian database of over 15,000 isolates from human, animal, and environmental sources. The biggest cluster found was 926.2.1 (Additional file 1 Table S1, and Table S2) and all strains in this cluster had higher outcompeting capacities. In the Canadian database, strains from this cluster were isolated from chickens, raccoons, and humans. Further studies that would extend the characterization of strains occurring from different sources are needed 
to make conclusions about the public health impact of the ability of a given strain to compete for chicken colonization. CGF profiles did not perfectly match outcompeting capacity, further illustrating the disparity that exists between strain genetic and phenotypic typing.

\section{Conclusions}

In this study, a combination of phenotypic and genetic characterization was used in order to identify traits that provide $C$. jejuni strains with a competitive advantage when colonizing the chicken gastrointestinal tract. It clearly demonstrated the extent of the variability of phenotypes found in chicken $C$. jejuni strains. Our results confirm that some C.jejuni strains are better competitors than others. Strains with high autoagglutination, chemotaxis, adhesion, and invasion properties were the ones presenting the highest outcompeting capacities. Some genes could be associated with a strain's outcompeting capacities such as the arsenic resistance gene arsC. The role and direct involvement of the identified genes in the mechanism that confers some $C$. jejuni a competitive advantage when colonizing the chicken gut still needs to be assessed in further studies.

\section{Additional file}

Additional file 1: Table S1. Describes, for each typed strains, the presence or absence of all 40 genes tested by PCR; In red are the genes missing from the strains and in green the genes present; The last column indicates the CFG cluster identification according to the Canadian database. Table S2. Describes, for each cluster observed in this study, all meta-data available in the Canadian database.

\section{Competing interests}

The authors declare that they have no competing interests.

\section{Authors' contributions}

AT, with the exception of CGF, carried out all experiments presented in this manuscript, actively participated in the design of the experiment, and co-drafted the paper. PF actively participated in the design of the experiment and co-drafted the paper. ET carried out the CGF and reviewed the manuscript. SLW participated in the design of the experiments and reviewed the manuscript. EG participated in the study design and reviewed the paper. SQ participated in the design of the experiments and reviewed the paper. AL is the senior scientist supporting this manuscript, actively participated in the design of the experiments, and reviewed the paper. All authors read and have approved the final manuscript.

\section{Acknowledgements}

We would like to thank the following organizations for their financial support: Ministère de l'Agriculture et des Pêches du Québec (MAPAQ), the Centre de Recherche en Infectiologie Porcine et Aviaire (CRIPA), and Natural Sciences and Engineering Research Council of Canada (NSERC grant no: 130565330; for the NSERC Industrial Research Chair in Meat Safety and other financial partners).

\section{Author details}

${ }^{1}$ Department of Pathology and Microbiology, NSERC Industrial Research Chair in Meat-Safety (CRSV), University of Montreal, Veterinary Medicine Faculty, Saint-Hyacinthe, QC, Canada. ${ }^{2}$ Department of Pathology and Microbiology, Swine and Avian Infectious Disease Research Centre (CRIPA), University of Montreal, Veterinary Medicine Faculty, Saint-Hyacinthe, QC, Canada.
${ }^{3}$ Department of Pathology and Microbiology, Groupe de recherche et d'enseignement en salubrité alimentaire (GRESA), University of Montreal, Veterinary Medicine Faculty, Saint-Hyacinthe, QC, Canada. ${ }^{4}$ Agriculture and Agri-Food Canada, Food Research and Development Centre, St-Hyacinthe, QC, Canada. ${ }^{5}$ Public Health Agency of Canada, Laboratory for Foodborne Zoonoses, Lethbridge, AB, Canada.

Received: 24 November 2014 Accepted: 30 April 2015 Published online: 10 May 2015

\section{References}

1. Young KT, Davis LM, Dirita VJ. Campylobacter jejuni: molecular biology and pathogenesis. Nat Rev Microbiol. 2007;5:665-79.

2. Rosenquist H, Boysen L, Galliano C, Nordentoft S, Ethelberg S, Borck B. Danish strategies to control in broilers and broiler meat: facts and effects. Epidemiol Infect. 2009;137:1742-50.

3. MAPAQ. Bilan annuel 2010-2011 - Toxi-infections alimentaires. 2012.

4. Hermans D, Pasmans F, Heyndrickx M, Van Immerseel F, Martel A, Deun $K$, et al. A tolerogenic mucosal immune response leads to persistent Campylobacter jejuni colonization in the chicken gut. Crit Rev Microbiol. 2012;38:17-29.

5. Coward C, van Diemen PM, Conlan AJ, Gog JR, Stevens MP, Jones MA, et al. Competing isogenic Campylobacter strains exhibit variable population structures in vivo. Appl Environ Microbiol. 2008;74:3857-67.

6. Calderón-Gómez LI, Hartley LE, McCormack A, Ringoir DD, Korolik V. Potential use of characterised hyper-colonising strain(s) of Campylobacter jejuni to reduce circulation of environmental strains in commercial poultry. Vet Microbiol. 2009;134:353-61.

7. Hermans D, Van Deun K, Martel A, Van Immerseel F, Messens W, Heyndrickx $\mathrm{M}$, et al. Colonization factors of Campylobacter jejuni in the chicken gut. Vet Res. 2011;42.

8. Guerry P, Ewing CP, Schirm M, Lorenzo M, Kelly J, Pattarini D, et al. Changes in flagellin glycosylation affect Campylobacter autoagglutination and virulence. Mol Microbiol. 2006;60:299-311.

9. Hendrixson DR, DiRita VJ. Identification of Campylobacter jejuni genes involved in commensal colonization of the chick gastrointestinal tract. Mol Microbiol. 2004;52:471-84.

10. Pope C, Wilson J, Taboada EN, Mackinnon J, Felipe Alves CA, Nash JH, et al. Epidemiology, relative invasive ability, molecular characterization, and competitive performance of Campylobacter jejuni strains in the chicken gut. Appl Environ Microbiol. 2007;73:7959-66.

11. Thibodeau A, Fravalo P, Garneau P, Masson L, Laurent-Lewandowski S, Quessy S, et al. Distribution of Colonization and Antimicrobial Resistance Genes in Campylobacter jejuni Isolated from Chicken. Foodborne Pathog Dis. 2013;10:382-91.

12. Chaloner G, Wigley P, Humphrey S, Kemmett K, Lacharme-Lora L, Humphrey $T$, et al. Dynamics of dual infection with Campylobacter jejuni strains in chickens reveals distinct strain-to-strain variation in infection ecology. Appl Environ Microbiol. 2014;80:6366-72.

13. Thibodeau A, Fravalo P, Laurent-Lewandowski S, Guevremont E, Quessy S, Letellier A. Presence and characterization of Campylobacter jejuni in organically raised chickens in Quebec. Can J Vet Res. 2011;75:298-307.

14. Byrne CM, Clyne M, Bourke B. Campylobacter jejuni adhere to and invade chicken intestinal epithelial cells in vitro. Microbiology. 2007;153:561-9.

15. De Hoon MJ, Imoto S, Nolan J, Miyano S. Open source clustering software. Bioinformatics. 2004;20:1453-4.

16. Saldanha AJ. Java Treeview-extensible visualization of microarray data. Bioinformatics. 2004;20:3246-8.

17. Juteau P, Tremblay D, Ould-Moulaye CB, Bisaillon JG, Beaudet R. Swine waste treatment by self-heating aerobic thermophilic bioreactors. Water Res. 2004;38:539-46.

18. Taboada EN, Ross SL, Mutschall SK, Mackinnon JM, Roberts MJ, Buchanan CJ, et al. Development and Validation of a Comparative Genomic Fingerprinting Method for High-Resolution Genotyping of Campylobacter jejuni. J Clin Microbiol. 2012;50:788-97.

19. Ahmed IH, Manning G, Wassenaar TM, Cawthraw S, Newell DG Identification of genetic differences between two Campylobacter jejuni strains with different colonization potentials. Microbiology 2002;148:1203-12. 
20. Wang $L$, Jeon B, Sahin O, Zhang Q. Identification of an arsenic resistance and arsenic-sensing system in Campylobacter jejuni. Appl Environ Microbiol. 2009;75:5064-73.

21. Arsanilic acid - MIB \#4 [http://www.inspection.gc.ca/animals/feeds/medicatingingredients/mib/mib-4/eng/1330714521085/1330716893318]

22. Mallik S, Virdi JS, Johri AK. Proteomic analysis of arsenite - mediated multiple antibiotic resistance in Yersinia enterocolitica biovar 1A. J Basic Microbiol. 2012:52:306-13.

Submit your next manuscript to BioMed Central and take full advantage of:

- Convenient online submission

- Thorough peer review

- No space constraints or color figure charges

- Immediate publication on acceptance

- Inclusion in PubMed, CAS, Scopus and Google Scholar

- Research which is freely available for redistribution 